\title{
How Designed Communication Supports New Product \& Service Development
}

\author{
Olaf Gaus ${ }^{1}$, Bernd Neutschel ${ }^{2}$, Matthias G. Raith ${ }^{1}$, Sándor Vajna ${ }^{2}$ \\ ${ }^{1}$ Faculty of Economics and Management, Otto-von-Guericke-University, Magdeburg, Germany; ${ }^{2}$ Institute for Machine Design In- \\ formation Technologies in Mechanical Engineering, Otto-von-Guericke-University, Magdeburg, Germany. \\ Email: gaus@ovgu.de
}

Received May, 2013

\begin{abstract}
Design is communication. In a traditional sense of design theory this idea is based on a product related perspective, stating that good design must speak a language that is understood by the recipient. The aesthetics of the design catches his interest and opens his mind as a prerequisite for his willingness to enter into a dialogue. From symbols and images an argument is derived, rationally understandable, convincing and finally condensed in a message. This process is triggered by the product design. It communicates a value proposition for the recipient combined with a demand to buy the product it refers to. At the moment of the purchase decision a transformation takes place and the value proposition turns into a benefit, the design into the product utility and the recipient into a customer. It will be argued that this process retains its validity even if communication itself is considered as a product.
\end{abstract}

Keywords: New Product \& Service Development; Designed Communication; Value Added Support

\section{Introduction}

Over the last decade the subject areas of product development and entrepreneurship research have converged constantly. Both disciplines have benefited greatly from the production of knowledge during the research-intensive 1980s. Based on these methodological foundations we observed a diversification of topics within the disciplines in the 1990s coupled with an applied research approach for industrial needs. Considering the methodological foundations precisely, it can be said that in the engineering science the product and process development, based on the introduced standards of New Product Development [1] and Design for Manufacture and Assembly (DFMA) [2], still plays the crucial role. From a cross-discipline point of view a methodological parallel with the entrepreneurship research is evident. The distinctive characteristics believed to be associated with entrepreneurship like "growth" and "innovation" $[3,4]$ and came to their foundations also in the $80 \mathrm{~s}$. A temporal exception is the "entrepreneurial process" that has been put on the research agenda after the turn of the millennium [5]. However, in both fields of science a shift in research interest is recognizable since the 1990s, characterized by a preferred orientation towards applicationoriented problems, coupled with a strong focus on product development. As much as this decision is understandable in favour of a product-oriented industry with a high demand for problem solving, so little has been invested in New Product Development for the service economy as a whole $[6,7]$ that increasingly grew in conjunction with the global knowledge society since the end of the last century and became more and more important - socially, culturally and in terms of economic growth. As a conclusion from this trans disciplinary analysis the idea developed of using the theoretical foundations of the product and process optimization in combination with entrepreneurial tools and methods to design service-oriented university start-ups.

\section{A Strategy of Pre-Entrepreneurial Value Creation}

To promote the promising synergies arising from the collaboration of young and elderly entrepreneurs, the University of Magdeburg in Germany initiated the project titled "Senior- \& Junior preneurship"(SeJu), which is funded by the Ministry of Science and Economics of the State of Saxony-Anhalt. By accessing an educational platform for inter-generational interaction, senior preneurs have the opportunity not only to engage in lively interactions concerning their entrepreneurial ideas, but also to benefit from personal standpoints, current academic knowledge in technology and business, and, last but not least, from the enthusiasm of future entrepreneurs. 
SeJu is a university-based project that facilitates technically oriented start-ups of founders with a professional, yet non-entrepreneurial background. Specifically, SeJu offers the possibility to develop product ideas technically while, at the same time, constructing a business plan for a firm to successfully implement a mature product on the market. The project extends the intensive collaboration since the year 2005 at the University of Magdeburg in Germany between the chair of Information Technologies in Mechanical Engineering (Sándor Vajna) of the Faculty of Mechanical Engineering and the chair of Entrepreneurship (Matthias Raith) of the Faculty of Economics. Taking advantage of the synergies already mentioned, participants obtain the opportunity of learning how to create high-growth start-ups.

To get the process started a senior preneur actively has to be determined by acquisition who offers a technical based product idea to SeJu that is going to be proved as well as assessed by the project team concerning its implementation options. Once the test results confirms a high level of technical and economic quality of the idea it comes to a procedural process that helps to consider whether one may expect an entrepreneurial opportunity in case of a product launch.

To get an idea of how the development process proceeds at SeJu, it can be briefly described as follows (Figure 1):

- A seniorpreneur is applying with a technical product idea.

- The idea is evaluated with the knowledge of the participating science departments and checked for viability.

- After having accepted the project an interdisciplinary team of students is put together and joined with the seniorpreneur.

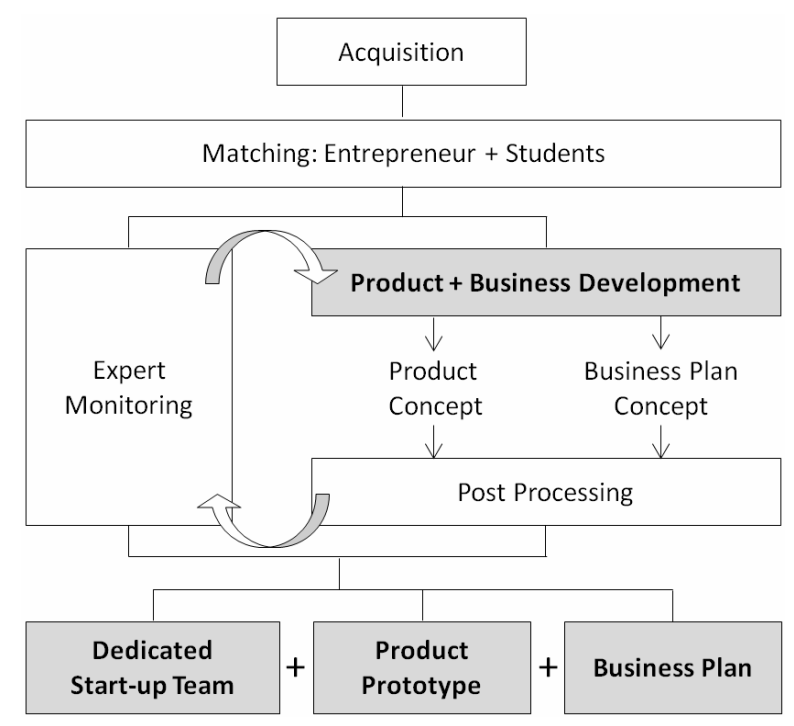

Figure 1. SeJu development process.
- Technical product development and business plan design are running in parallel.

- Experts monitor the progress of the project.

- Product concept and business plan are developed.

- The results are evaluated by members of the scientific staff.

- By working together on a development task that is meant to be technically and economically realized, participants grow as an entrepreneurial team despite the differences in knowledge and age.

In addition to business plans and product prototype a multi-disciplinary entrepreneurial team has been built, ready to start a well planed and promising product-tomarket strategy.

The product creation process is based on the principles of Integrated Product Development (IPD) [8]. IPD requires a consistent vision of the entire product life cycle, meaning that the interaction between product and process is paramount. As a consequence, the product developer is faced with the task to synchronize the creation of a product with the production process all in one. The derived goal is to create a consistent product, while ensuring a demand-oriented production, use and disposal.

These principals are based on different views on the product to be developed. This allows the creation of all the essential features of the product and its required forms. On the functional sector all key items are permanently controlled with a view to criteria like form, function, performance, manageability, reliability and security, value for money, manufacturing ability, maintainability and sustainability.

This necessarily requires engineering design methods and tools as Blanchard [9] describes it with special reference to its integration in process simulation. The embedded process was generally described by Clark, Fujimoto [10] by regarding four major stages of development: concept development, product planning, product engineering, and process engineering as well as the critical linkages within and across them. The special feature of SeJu is that the process just described is duplicated and connected in parallel in terms of running the product and business development at the same time are taken into account the critical linkages [11].

\section{Same Procedure? From Product to Service Development}

According to the above-mentioned literature one could hardly answer the question how to design communication processes in order to develop a marketable intangible good like e.g. public or private services. The underlying methodological approach assumes to understand service as a product that can be developed and optimized in the same way. This means that communication is related to service like design does towards a product. Out of this 
follows the assumption that the development process in both cases behaves the same or at least similar and methods can be applied equally. This is in accordance with the probably best-known New Service Development Model (NSD) Gustafsson and Johnson came up with in 2003. They adapted and modified the New Product Development Stage-Gate Process [12] by adding further "gates" for cultural and organizational change.

Unlike Cooper's linear stage-gate process the NSD model by Gustafson and Johnson [13] suggests that additional criteria should be implemented which are called "cultural fit", "organizational change fit" and "strategy fit". These criteria are considered to have the function of a gate too in order to verify whether an idea will move to the next stage of new service development. Finally, the NSD model also considers the customer's needs and therefore incorporates a needs-identification stage labeled "Immerse Yourself in Customers". From the perspective of the communication approach that is emphasized in this paper, the NSD model by Gustafsson and Johanson can be optimized by the following modifications:

- The NSD model remains static and hierarchically structured according to a top down pattern similar to Cooper.

- There are no feedback loops between the various gates/stages scheduled, neither intern the model nor in exchange with externals, such as suppliers or customers.

- There is neither a discourse nor an interaction between suppliers and customers; also the supply chain is not integrated into the model.

A designed communication approach depends on integrating the following elementary components to develop a high-value generating NSD model [14]:

- The starting "focus" needs to discuss the service idea in terms of a valuable entrepreneurial opportunity.

- This discussion takes place in all "fitting elements" on the strategy, change and cultural level of the model and is extended to other business-related stakeholders as there are: the bank, investors, business angels, suppliers, competitors, future employees, prospective customers on regional, national and international markets, think tanks (e.g. universities as a future $\mathrm{R} \& \mathrm{D}$ resource), etc.

On the level of the "Market Test \& Launch" of the NSD model it is necessary to feed back all data and conclusions to the level of "Strategy Fit": In case, the market test leads to the conclusion that there is indeed a demand for the offered service, but a market penetration seems to be too costly for the initiating enterprise then new strategies for the commercialization of the entrepreneurial opportunity should be found. One example for a possible alternative utilization is joint ventures with competing enterprises. However, this can be a reasonable strategic decision since it is known that entrepreneurial designed concepts on the basis of new knowledge is the strongest indicator for economic growth.

\section{Value Innovation Depends on Communication}

The above mentioned SeJu project has led to the result that a portfolio of product prototypes has emerged. They are ready to be prepared for a recovery in the market. Since they parallel have been equipped with custom-made business plans a decision can be made either to bring them into the market by initiating a start-up or to commercialize the product by selling it to an existing enterprise operating in a relevant field of the market. By discussing the pros and cons of this decision it becomes apparent that almost any product in the portfolio invites the developers to think about how to create a value-added service with its own value function which implies that according to any product a service concept would have to be created.

This challenge raises the question again of whether to develop a service concept the same process can be used as for product development. Referring back to the New Service Development discussion in the late nineties of the last century up to the beginning of the new millennium [15-19] the idea came up that a service concept plays a key role in service design and development. The service concept in detail should define the how and what

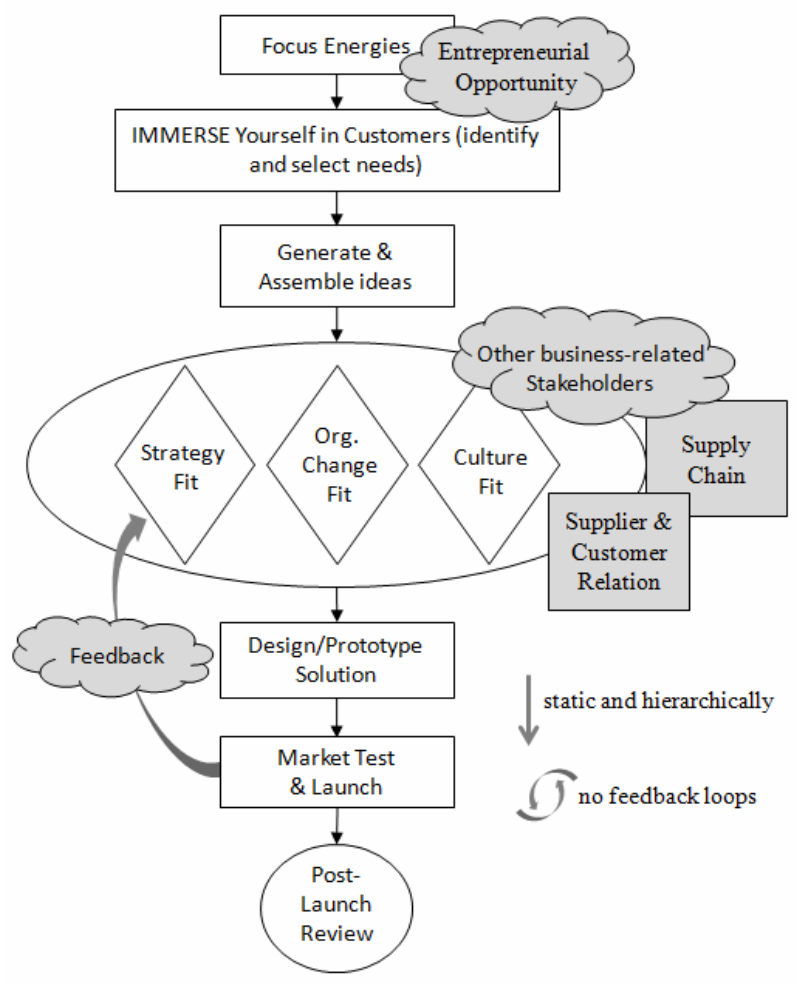

Figure 2. Modified NSD model in accordance with gustafsson and johanson [13]. 


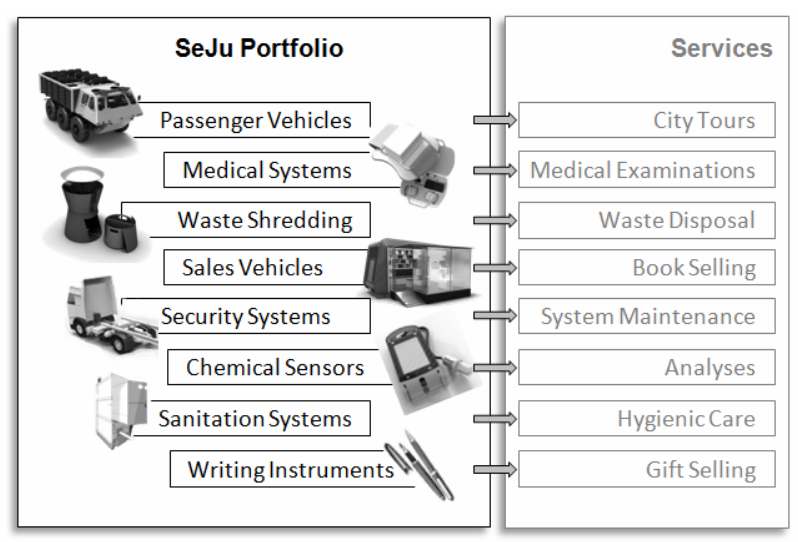

Figure 3. SeJu product portfolio and resulting services.

of service design, and helps to mediate between customer needs and organizations' strategic intend [20]. This credo still describes the business requirement for a high-value service concept. It indeed inspires the question if and how NSD sets up new concepts for service offerings. Is it the customer's viewpoint or the offerer's perspective that affects the priorities in the creation of a service concept most significantly? This question is relevant to the customer's decision to buy or not to buy a specific service due to his idea of value innovation.

As a consequence of this one can state that the service concept brings strategic intent into service design planning. A major guideline for constructing such a concept is to understand what customers want and expect. This leads to two neglected questions in service design research: How should a communication strategy be integrated into a service concept and how is the latter to be considered best as a harmonious part of design. However, if you call yourself the mentioned service design process to mind and look at it from the position of the customer there occurs a "service in the mind" [21] as the customer's expectations of what and how a service should be as well as a critical appraisal if the customer's needs may be fulfilled. Three main criteria are playing a leading role: How is the service communicated? (How does it feel to interact?) Does the offered service meet my needs? (Am I the right customer?) Is the service worth the price? (Are there better, cheaper and nicer services available in order to satisfy my needs?). Summing up all these questions, there are two strategic requirements for the design of a service concept (Figure 4): First, on the communication level the utility function of the service and its superiority in the competition must be accurately and comprehensible described for the customer. This operation requires to appealing to the intellect of the customer with rational arguments in first instance. Second, the value perception needs to address the customers' sense of aesthetics by offering a combination of pleasant personal touch and desireable images via communication.

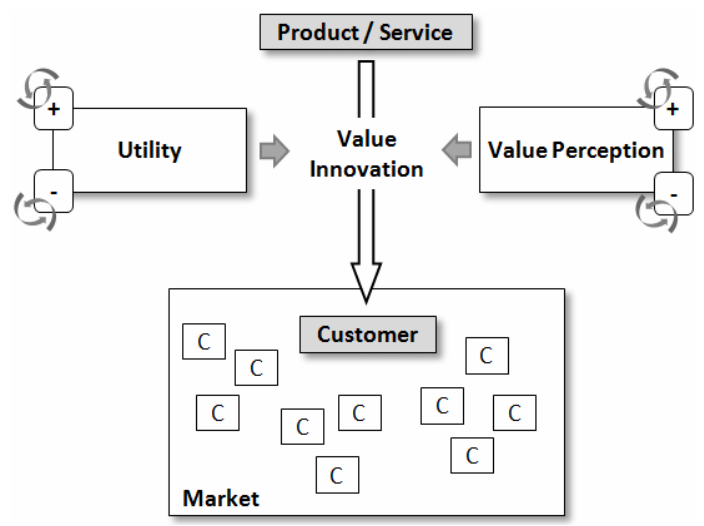

Figure 4. Design approaches for communication processes.

\section{The Importance of Customer Feedback}

Revisiting the "cultural fit", Gustafsson and Johanson came up with in their reflections on a modern NSD approach it seems to be quite obvious that every successful service concept has to deal with interaction strategies. The literature on market orientation and customer oriented service development argues for customer input throughout the whole development process [22-24]. At the same time there is evidence in part of the NSD literature that customer interaction can increase service success $[25,26]$. A more or less open question still is, at what stages of the NSD the customer should be obtained. In the by the authors of this paper modified model of Gustafsson and Johanson the customer interaction is called "feedback".

It is located between the stages of the "Market Test" and the "Strategy Fit". The substantiation for this modification does not rule out that there may be reasons for further "feedbacks" on other stages within the process. The selection of this stage is due to the observation that the customer mainly decides on the basis of rational arguments on the one hand and the touch of the customer's sense of aesthetics via communication on the other hand. During the NSD process the service design is completed not before the "Strategy Fit" is planed. However, since the strategy depends on the quality of the empirical data, as far as the assessment of the market and the customers is concerned, all necessary information (feedback) has to be collected in this moment before the service is placed on the market.

The collecting of information is a critical momentum from the perspective of the entrepreneur. But - and this is important - not from the customer's perspective. The information-deficit model of behavior change (knowledgedeficit model) contends that poor decisions are made because people lack the information that would enable them to make a better choice. However, both marketing and the behavioral sciences have shown that the information-deficit model is obviously flawed. Instead of this 
behavioral economists and neuroscientists attributes these 'limitations' in human decision-making to two distinct types of thinking: automatic and reflective [27]. The 'automatic system' is fast, effortless and often emotionally charged. Because people have little control over their thoughts in the state of the 'automatic system', there is also little control over the behaviors that are occurring in this state of mind. Decisions are made, so to say, without thinking. Also the intensity of thought reflection is declining [28].

In contrast to that the 'Reflective System' is significantly slower, effortful and consciously monitored as well as deliberatively controlled [27]. The 'Reflective System' is also able to monitor the activity of the 'Automatic System'. A rational economic thinker would always consult his 'reflective system', but most people prefer to rely on their 'automatic system' in everyday life [29].

With this in mind it is quite likely that the NSD process would profit from being designed under the consideration of the above suggested strategy. In order to communicate the value innovation to the customer successfully it seems to be promising to use the findings of neuroscience. Economists have further developed Kahneman's system and it suggests that there are two operating dimensions when it comes to decision-making, distinguishing between a cognitive one in terms of rational thought or reason and an affective one that concentrates on feelings or emotions.

\section{The Commercialization of Services}

Innovation is presumed to be the sole province of service producing enterprises, even though the interaction with the customer - as described above - is an important part of the service innovation process and, of course, a key success factor of new services [30,31]. This suggests that new NSD models should incorporate the mechanism of customer-producer interactions as well as strategies to be successfully implemented [32] within value innovative new services.

As being said in the foregoing paragraphs the interesting methodological tools for creating a highly workable service process (Figure 5) can be derived from various scientific disciplines such as economics, especially behavioral economics and marketing, psychology, especially neuroscience and finally, what has not been discussed yet, the research coming from entrepreneurship and innovation. In this context one of the core insights is that technology innovation is not a prerequisite for value innovation. The task is to answer two questions: Is the customer being offered radically superior value? And is the price level accessible to a sufficient number of customers in the targeted market? [33]. Of course these questions belong to the basics of business planning but nevertheless they depend on having analyzed the innova- tion potential of a service idea. This is the moment when research and development comes into play.

Any successful utilization depends on the communication with transfer partners. Innovative products or services are not taken up by companies without reason. Promising co-operations have to be analyzed in advance, especially regarding the willingness and the ability of a product-to-market strategy. This is important because not only a product has to be innovative in order to be successful, but also the market. In other words, the customer wants to understand why a product innovation is a value innovation (is a buy worth the money?).

If this condition is fulfilled for the customer, a carefully selected transfer partner would be able to use his company's resources, e.g. production, sales and marketing, to realize a value creation process in short time. Regardless of which form of transfer is chosen, an experienced entrepreneur or manager is always required to design and implement the described process of value-adding support.

\section{The Aesthetic Impression Dominates the Buying Interest}

In order to test the exceptional utility of a product or a service due to the customer's response it became more and more common sense in entrepreneurship literature that a "Buyer Utility Map" [34] would be necessary in order to timely carry out a complete customer needs analysis. From the perspective of the offered there are six utility levers to be considered to satisfy the customer's needs: Customer productivity, simplicity convenience, risk, fun and image and environmental friendliness. Moreover, the seller has to keep in mind that his customer regards every mentioned utility lever through the eyes of the six stages of the buyers experience cycle: Purchase, delivery, use, supplements, maintenance and disposal. Taking these utility levers and stages of the buyer experience cycle back to value innovation Kim and Mauborgne explicitly point out that "Value innovation is

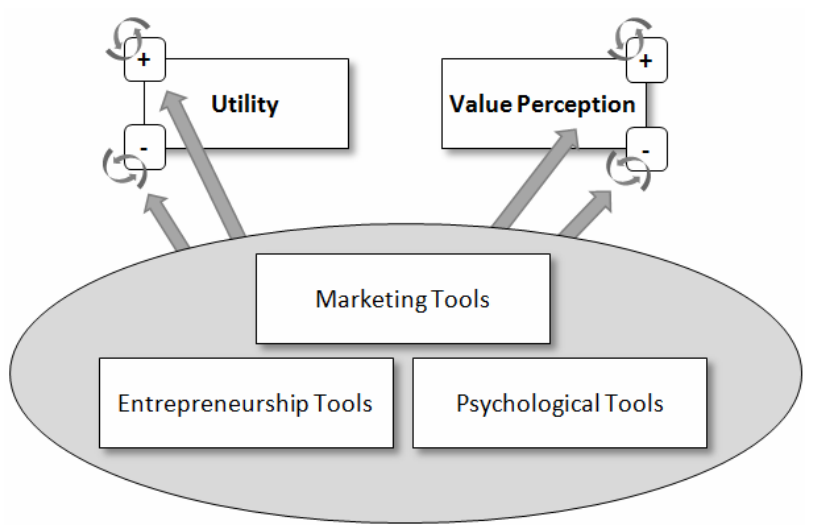

Figure 5. Interdisciplinary set of value creation tools. 
not the same as technology innovation." Rather, it is important "to create a strategic profile that passes the initial litmus test of being focused, being divergent, and having a compelling tagline that speaks to buyers."

This request rejects directly to the importance of communication between the product or service on the one hand and the customer on the other hand. The first acquaintance between a product or service and a potential customer usually takes place in the media. This very first moment of awareness is embossed on the side of the buyer - in this moment still at the stage of a interested observer - through a bounded rationality. This means that instead of a pure logical and rational model of decision the importance of the influence of a "gut feeling" [35] is underrated. Decisions are therefore intuitively mainly made on the basis of rules of thumb, which the rational decision-making strategies are followed later on. Against this background, it is to be understood that the visual perception of a product or service has its own aesthetic importance in the development of interest in buying or making a purchase decision. Strictly speaking, product or service aesthetics created by a product's appearance, influenced by material, color, proportion, size or shape not only determines the relationship between the potential buyer and the product or service [36] and decides on the proverbial "first impression" for potential customers. These aesthetic qualities can measurably influence customers' preference judgments and choice [37,38].

In respect of the before mentioned findings concerning the NSD process, especially the addition of feedback loops between supplier and customer in the model of Gustafsson and Johanson (Figure 2) we developed a product service we developed a product service that was assigned to the product "WildPen" from the Seju product portfolio (Figure 3, Writing Instruments, Service: Gift selling). In order to give a first proof to our hypothesis that there definitely exists a significant influence of aesthetic qualities and customers' preference judgments and choice we conducted a pre-test, in which we asked for the basic willingness to buy a product as a gift for someone else.

Basis for the decision of the respondents was a framed advertisement (Figure 6). The pre-testing was inspired by the criteria of the two best-known tests to measure visual aesthetic sensitivity as there are the Test of Aesthetic Judgment Ability [39] and the Centrality of Visual Product Aesthetics Scale (CVPA) [37]. The concept for the advertisement has been taken from the business plan was written concurrently with the product design of the WildPen. The image-forming criteria for this product were thus:

- conservative customer based on values and traditions

- write-esthete

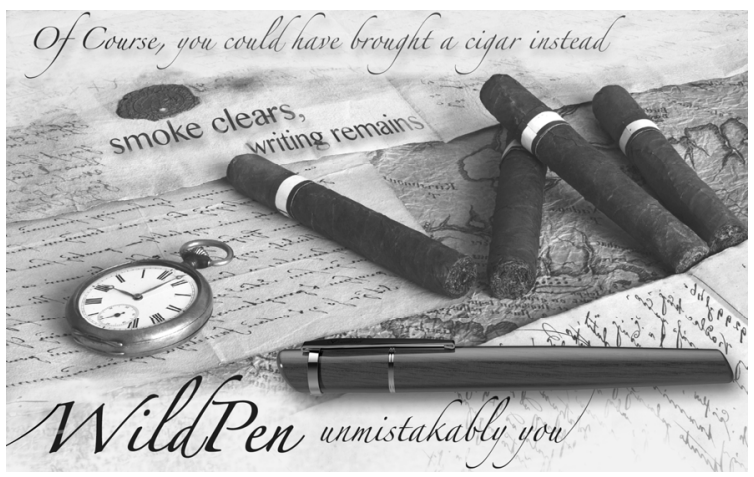

Figure 6. Influence of aesthetic qualities and customers' preference judgments.

- middle to older aged

- design-oriented

- self-confident

- image-conscious

- brand conscious

The issues the respondents were confronted with allocated into the two areas "aesthetic impression" and "product benefits". In order to meet the image-forming criteria of the WildPen the product designers made the pen look like a cigar. From a perspective of visual product aesthetics this decision had a negative impact on the overall assessment of the experimentees who should decide on a Likert scale from 1 (applies exactly) to 5 (applies not at all) if they would buy the WildPen as a gift for someone else. The respondents answered the following six questions:

- I will buy the WildPen as a gift mainly because of the aesthetic impression of the product presentation.

- I will buy the WildPen as a gift mainly because of the convincing product benefits.

- I will buy the WildPen as a gift because of both, the aesthetic impression of the product as well as the convincing product benefit.

- I will not buy the WidlPen as a gift because the aesthetic impression of the product presentation does not touch me.

- I will not buy the WildPen as a gift because the product benefits do not convince me.

- I will not buy the WildPen as a gift because neither the aesthetic impression of the product presentation touches me nor the product benefits appear to be convincing.

The result of the pre-testing shows that all respondents did not feel encouraged by the advertising and by the aesthetic impact of the presentation to buy the WildPen as a gift (Figure 7). This result is not only to explain with the changing buying perspective (I do not buy for myself, but it's a gift for someone else) but also on the associated psychological reflection (I do not know anyone who likes a pen that looks like a cigar). Although the 


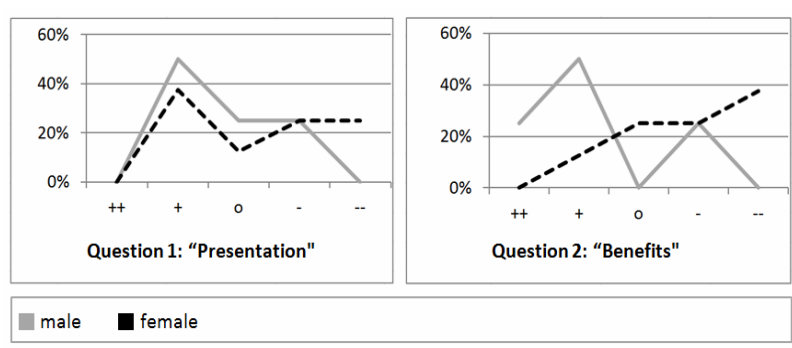

Figure 7. Selection of the pre-test results.

image-forming criteria have been adequately addressed in the advertising the respondents gave the clear feedback that the image of a cigar as such is considered very negative. It dominates the therewith associated product and does not support a buying decision, but a rejection of the purchase.

\section{Conclusions}

The value of an entrepreneurial service innovation promotes the growth of a company. This results in an assumed value, which is appreciated at the time of sale on the basis of a current and carefully developed business plan. A research goal is, on the one hand, to use evaluation models for value taxation, and, on the other hand, to develop cooperative negotiation models, which allow differentiated solutions and support. Methodological knowledge of this type pays off when it comes to negotiating and enforcing best value strategy. From case to case it may be advisable to opt for different negotiation objectives. For instance, an exit strategy may be useful if a product innovation is to be sold for one-time payment under the assignment of all rights. But more important is the use of scalable business models that allow for investments in research and development driven companies.

In terms of business opportunities that can be recognized both for the development of products and services for a value creation opportunity, it is essentially important to involve the customer perspective as early as possible into the product or service development as well as into the business planning. Since this study primarily considers the service development and customization of the design process to improve the value adding opportunity it should be noted, first, that the NSD process requires an earlier, systematic and better quality of customer feedback. Second, the integrative interaction of service and business plan design can be optimized in terms of feedback processing and adjustment of the value proposition. Third, and finally, the influence of the aesthetic perception of a product or service on the purchase decision of a potential customer is not sufficiently explored. As discussed in this study, the pre-testing has shown the influence of the perception of design as a very powerful communication and decision-factor. It is there- fore important that the available tests for assessing aesthetic ability may be integrated systematically as early as possible in the product, service and business plan development. This is still a desideratum of research.

\section{Acknowledgements}

The project „Senior- \& Junior preneurship“ (SeJu) is funded by the European Social Fonds (ESF) and the Ministry of Science and Economics of the State of Saxony-Anhalt, Germany. Key considerations on the issue of a "Entrepreneurial University" are due to the cooperation with the project "Universities as Enterprises" (Uni:prise) funded by the Ministry for Education and Research of the Federal Republic of Germany.

\section{REFERENCES}

[1] Booz, Allen and Hamilton, "New Product Management for the 1980s," New York, Booz Allen Hamilton Inc, 1982.

[2] G. Boothroyd and P. Dewhurst, "Early Cost Estimating in Product Design," Journal of Manufacturing Systems, Vol.7, No. 3, 1988, pp. 183-191. doi:10.1016/0278-6125(88)90003-9

[3] P. F. Drucker, "Innovation and Entrepreneurship," Practice and Principles, Oxford, 1985.

[4] W. J. Baumol, "Business Behaviour, Value and Growth," New York, 1959/ 1966.

[5] R. A. Baron and S. A. Shane, "Entrepreneurship: A Process Perspective," 2nd Edition, Thomson South-Western, Mason, Ohio, 2007.

[6] C. J. Easingwood, "New Product Development for Service Companies," Journal of Production and Innovation Management, Vol. 4, 1986, pp. 264-275. doi:10.1016/0737-6782(86)90005-6

[7] P. Kristensson, J. Matthing and N. Johansson, "Key Strategies for the Successful Involvement of Customers in the Co-creation of New Technology-based Services," International Journal of Service Industry Management, Vol. 19, No. 4, 2008, pp. 474-479.

doi:10.1108/09564230810891914

[8] S. Vajna and T. Naumann, "Implementation of the New IPD Study Course at the Otto-von-Guericke University Magdeburg, Design Applications in Industry and Education," Proceedings of the 13th International Conference on Engineering Design (ICED 01), Glasgow, edited by S. Culley, A. Duffy, C. McMahon, K. Wallace, 2001, pp 277-284.

[9] B. S. Blanchard, "System Engineering Management," Third Edition, Wiley, Hoboken, 2004, pp. 201-206.

[10] K. B. Clark and T. Fujimoto, "Product Development Performance: Strategy, Organization and Management in World Auto Industry," Harvard Business School, 1991.

[11] B. Neutschel, O. Gaus, M. G. Raith and S. Vajna, "Value-Focused Thinking - Combining Product Development and Entrepreneurial Product-to-Market Strate- 
gies," in: Proceedings of the ASME 2012 International Design Engineering Technical Conferences and Computers and Information in Engineering Conference, Chicago, Illinois, August 12-15, 2012, Vol. 7, 9th International Conference on Design Education, ASME 2013, DETC2012-70925.

[12] R. G. Cooper, "Third Generation New Product Processes," Journal of Product Innovation Management, Vol. 11, 1994, pp. 3-14. doi:10.1016/0737-6782(94)90115-5

[13] A. Gustafsson, M. D. Johnson, "Competing in a Service Economy: How to Create a Competitive Advantage Through Service Development and Innovation," San Francisco, CA, Wiley, 2003.

[14] D. Audretsch, "Innovation and Industry Evolution," MIT Press, Cambridge, 1995.

[15] J. H. Donnelly, L. L. Berry and T. W. Thompson, "Marketing Financial Services,” Irwin, Homewood, II, 1985.

[16] E. .E. Scheuing and M. E. Johnson, "New Product Development in Financial Institutions," International Journal of Bank Marketing, Vol. 7 No. 2, 1989, pp. 17-21. doi:10.1108/EUM0000000001454

[17] J. Sundbo, "The Organisation of Innovation in Services," Roskilde University Press, Roskilde, Denmark, 1998.

[18] B. Edvardsson, A. Gustavsson, M. D. Johnson and B. Sandén, "New Service Development and Innovation in the New Economy," Studentlitteratur, Lund, Sweden, 2000.

[19] S. Gupta and M. Vajic, "The contextual and dialectical nature of experiences," In: J. Fitzsimmons, M. Fitzsimmons, (Eds.), New Service Design. Sages, Thousand Oaks, CA, 2000, pp. 33-51.

[20] R. Johnston and G. Clark, "Service Operations Management," Prentice-Hall, Harlow, UK, 2001.

[21] G. Clark, R. Johnston and M. Shulver, "Exploiting the Service Concept for Service Design and Development," in J. Fitzsimmons, M. Fitzsimmons, (Eds.), New Service Design, Thousand Oaaks, CA, Sage, 2000, pp. 71-91.

[22] B. J. Jaworski and A. K. Kohli, "Market Orientation: Antecedents and Consequences," Journal of Marketing, Vol. 57, No. 3, 1993, pp. 53-70. doi:10.2307/1251854

[23] B. A. Lukas and O. C. Farell, "The Effect of Market Orientation on Product Innovation," Journal of the Academy of Marketing Science, Vol. 28, No. 2, 2000, pp. 239-47. doi:10.1177/0092070300282005

[24] S. F. Slater and J. C. Narver, "Does Competitive Environment Moderate the Marketing Orientation-performance Relationship?" Journal of Marketing, Vol. 58, No. 1, 1994, pp. 46-55.

[25] E. von Hippel, "The Sources of Innovation," Oxford University Press, New York, NY, 1988.
[26] K. E. Gruner and C. Homburg, "Does Customer Interaction Enhance New Product Success?" Journal of Business Research, Vol. 49, No. 1, 2000, pp. 1-14. doi:10.1016/S0148-2963(99)00013-2

[27] D. Kahneman, "A Perspective on Judgment and Choice: Mapping Bounded Rationality," American Psychologist, No. 58, No.9, 2003, pp. 697-720. doi:10.1037/0003-066X.58.9.697

[28] C. Camerer, G. Loewenstein and D. Prelec, "Neuroeconomics: How Neuroscience Can Inform Economics," Journal of Economic Literature, Vol. 43, No. 1, 2005, pp. 9-64. doi: $10.1257 / 0022051053737843$

[29] R. H. Thaler, Sunstein and C. R. Nudge, "Improving Decisions about Health, Wealth and Happiness," Yale University Press, London, 2008.

[30] C. T. Ennew and M. R. Binks, "The Impact of Service Quality and Service Characteristics on Customer Retention: Small Businesses and Their Banks in the UK," British Journal of Management, Vol. 7, No. 3, 1996, pp. 219-230. doi:10.1111/j.1467-8551.1996.tb00116.x

[31] C. R. Martin and D. A. Horne, "Level of Success Inputs for Service Innovations in the Same Firm," International Journal of Services Industry Management, Vol. 6, No. 4, 1995, pp. 40-56. doi:10.1108/09564239510096894

[32] V. Barabba, "Meeting of the Minds," Harvard Business School Press, Boston, M.A, 1995.

[33] W. C. Kim, R. Mauborgne, "Value Innovation: The Strategic Logic of High Growth," Harvard Business Review, Vol. 75, No. 1-2, 1997, pp. 102-112.

[34] W. C. Kim and R. Mauborgne, "Blue Ocean Strategy. How to Create Uncontested Market Space and Make the Competition Unrelevant," Harvard Business School Press, Boston M.A., 2005, pp. 120-125.

[35] G. Gigerenzer, "Good feelings, Short Cuts to Better Decision Making," New York, 2007.

[36] B. Hollins and S. Pugh, "Successful Product Design," London: Butterworths, 1990.

[37] P. H. Bloch, F. F. Brunel and T. J. Arnold, "Individual Differences in the Centrality of Visual Product Aesthetics: Concept and measurement," Journal of Consumer Research, Vol. 29, No. 4, 2003, pp. 551-565. doi: $10.1086 / 346250$

[38] S. Charters, "Aesthetics Products and Aesthetic ConSumption Markets and Culture," Vol. 9, No. 3, 2006, pp. 235-255. doi:10.1080/10253860600772255

[39] G. Barnossy, M. Johnston and M. Parsons, "The assessment of Aesthetic Judgment Ability," Empirical Studies of the Arts, Vol. 3, No. 1, 1985, pp. 63-79. doi:10.2190/1U13-U2DB-0BE3-A4FN 